\title{
ENTRE DOIS MODELOS: O CEFOR COMO ESCOLA DE GOVERNO
}

Rildo Cosson

Resumo: Instituído em 1997, o Centro de Formação, Treinamento e Aperfeiçoamento da Câmara dos Deputados (Cefor) tem desenvolvido amplas atividades educativas na área de formação e capacitação dos servidores. O crescimento contínuo dessas atividades e as novas reflexões sobre o papel dos órgãos de ensino da administração pública demanda que o Cefor repense a sua função a fim de se reconfigurar entre e além dos modelos disponíveis de escola de governo.

Palavras-chave: escola de governo, capacitação de servidores públicos, administração pública.

\begin{abstract}
Established in 1997, the Center for Training, Education and Improvement of the Chamber of Deputies (Cefor) has developed extensive educational activities in the area of training and capacity building of civil servants. The continued growth of these activities and new reflections on the role of the educational boards of the public administration demand that the Cefor rethink its function in order to reconfigure itself between and beyond the available models of school of government.
\end{abstract}

Keywords: school of government, civil servants' training, public administration.

\section{Introdução}

Houve um tempo em que a capacitação dos servidores públicos era realizada, quase que exclusivamente, com o propósito de desenvolver ou ampliar conhecimentos e habilidades inerentes ao funcionamento da burocracia estatal. A idéia básica era que o servidor necessitava ser treinado para prestar os serviços da maneira mais profissional possível. Todavia, as mudanças ocorridas no campo da educação e da administração pública nos últimos anos transformaram essa perspectiva meramente funcionalista em uma visão mais global e integrada do serviço público. Hoje, cresce o consenso de que a eficiência das instituições não pode ser medida apenas por um elevado percentual de atendimentos ou pela execução meramente

\footnotetext{
Doutor em Letras. Coordenador do Programa de Pós-Graduação do Centro de Formação, Treinamento e Aperfeiçoamento da Câmara dos Deputados. - rildo.mota@camara.gov.br
} 
burocrática das atividades, mas também por ações mais amplas, que incluem análises e diagnósticos de alta complexidade, formação de recursos humanos e confecção e implantação de novos, específicos e mais eficazes modelos de gestão no setor público.

Essa nova visão traz para as instituições e organizações propostas diversificadas de educação em ambiente profissional que, em geral, recusam a palavra treinamento em favor de outras denominações, como é o caso de universidades corporativas, centro de educação continuada, escola de governo e escola do legislativo, estas duas últimas entendidas como variantes de um mesmo tipo de órgão de capacitação do servidor público ${ }^{1}$. Tal perspectiva manifesta-se também na formação de associações e outras redes de cooperação, em que experiências são trocadas, dificuldades são discutidas e práticas bem sucedidas são compartilhadas, a exemplo da Rede Nacional de Escolas de Governo, articulada pela Escola Nacional de Administração Pública (Enap).

Nesse cenário de interação institucional diversificada e de troca de nomes para indicar novas práticas e concepções, a Câmara dos Deputados ainda mantém a antiga denominação de seu centro de treinamento. Entretanto, as alterações que ele vem sofrendo em sua estrutura e funcionamento mostram que se aproxima o momento de discutir uma denominação e configuração mais harmônicas. Este estudo é uma contribuição inicial para essa discussão que certamente também atinge, atingiu ou virá a atingir outras instituições da administração pública.

\section{Um pouco de história}

O Centro de Formação, Treinamento e Aperfeiçoamento da Câmara dos Deputados (Cefor) foi instituído pelo ato da Mesa n. 69, de 1997, com a finalidade de planejar, promover, executar e avaliar programas e atividades de recrutamento, seleção, atualização, aperfeiçoamento, especialização e desenvolvimento de recursos humanos. A criação de um centro de treinamento dos servidores, na área de recursos humanos, em molde adequado a servir de suporte básico à consolidação e ao desenvolvimento do plano de carreira, já estava prevista no art. 58, da resolução n. 21, de 1992. No entanto, foi apenas em 1997, após a discussão da indicação n. 190/95, que sugeria à Mesa a elaboração de um projeto de resolução criando a Escola de Formação do Servidor Público do Poder Legislativo, que se decidiu pela instituição do Cefor.

Para cumprir suas finalidades - que a apresentação de um folheto sobre o novo órgão, ainda em 1997, sintetizava como "capacitar o servidor com todos os instrumentos necessários para o auxílio da atividade legislativa, conscientizá-lo da importância de seu trabalho para a

\footnotetext{
1 Essa posição é referendada pela Associação Brasileira de Escolas do Legislativo que argumenta ser a escola do legislativo uma escola de governo no Poder Legislativo - www.portalabel.org.br. Também o art. $4^{\circ}$, do Dec. Presidencial n ${ }^{\circ}$ 5.707/2006, define como escolas de governo "instituições destinadas, precipuamente, à formação e ao desenvolvimento de servidores públicos, incluídas na estrutura da administração pública federal direta, autárquica e fundacional".
} 
sociedade e, acima de tudo, valorizá-lo como cidadão, ser humano" - o Centro foi criado com amplas competências. $\mathrm{O}$ arco de sua atuação vai desde a oferta de cursos de formação previstos no plano de carreira até a extensão de suas ações e objetivos à comunidade, incluindo a possibilidade de realização de convênios de intercâmbio e cooperação mútua com entidades e instituições públicas e particulares, a prestação de serviços relacionados às suas atividades e fins institucionais e o desenvolvimento e execução de programas, projetos e atividades de capacitação.

As primeiras atividades do Cefor consistiam em treinamento de servidores para atender às demandas gerais de qualificação dos órgãos da Câmara dos Deputados e na realização de concurso público. Tratava-se da oferta de cursos básicos, como de língua portuguesa, cursos de conteúdo legislativo, a exemplo de processo legislativo, e cursos pontuais gerados por solicitação direta de um ou outro setor da Casa. Em pouco tempo, esse quadro inicial foi se transformando, com o Cefor absorvendo outras demandas e desenvolvendo novas ações. A informatização da Casa, por exemplo, demandou um sem número de turmas de cursos voltados para o uso de processadores de texto, planilhas e correio eletrônico. Esforço que teve de ser repetido com a adoção do software livre Linux. A chegada de um grande número de novos servidores via concurso público exigiu a ampliação das atividades de treinamento, assim como a diversificação dos seus níveis de complexidade. A modernização das estruturas administrativas da Casa também despertou a necessidade de formação gerencial e a promoção de cursos de pósgraduação lato sensu na área da administração pública em parceria com universidades. Além disso, o Cefor buscou atender as necessidades de treinamento dos assessores parlamentares, um grupo flutuante de servidores contratados diretamente pelos deputados. A essas demandas internas somaram-se várias ações voltadas para o público externo. No caso do público escolar, por exemplo, tem-se o Parlamento Jovem - um programa de simulação parlamentar com estudantes do Ensino Médio de todo o País - e o estágio-visita - programa que traz alunos universitários para conhecer o funcionamento da Câmara dos Deputados. O público de outros legislativos é atendido com o trabalho de interação legislativa com as câmaras de vereadores. Agentes políticos os mais diversos encontram cursos e outras atividades de formação no programa de educação cidadã. Além de todas essas ações há, ainda, uma série de práticas de suporte a atividades desenvolvidas por outros órgãos da Câmara que envolvem questões educacionais.

O crescimento e a multiplicidade das ações do Cefor afetaram, ainda que timidamente, a sua estrutura interna. Quando da aprovação de seu regimento em 2000, o Cefor possuía uma diretoria e quatro coordenações: coordenação de recrutamento e seleção, coordenação de treinamento, coordenação técnico-pedagógica e coordenação de apoio técnico-administrativo. Em 2005, a coordenação de treinamento e a coordenação técnico-pedagógica foram fundidas em 
uma só e, em 2006, foi criada a coordenação de pós-graduação. Essa surgiu a partir da criação de um Programa de Pós-Graduação próprio em 2005, com o objetivo de centralizar os cursos de especialização, assim como configurar uma face mais acadêmica para o conhecimento que é produzido na Câmara dos Deputados. O Programa de Pós-Graduação do Cefor foi credenciado junto ao Ministério da Educação e dispõe, além dos cursos, de grupos de pesquisa e extensão, com livre participação de servidores da Casa e pesquisadores de outras instituições. Ainda em 2006, o Cefor deu início ao Programa de Desenvolvimento Gerencial, que compreende várias etapas na formação e atualização dos dirigentes de diversos níveis da estrutura organizacional da Câmara dos Deputados, e lançou, em parceria com o Instituto Universitário de Pesquisas do Rio de Janeiro (Iuperj), cursos de mestrado e doutorado interinstitucionais, com vistas a implantar um curso de mestrado próprio.

São essas e outras transformações de perfil e atividades que devem fazer o Cefor repensar a sua missão inicial de desenvolvimento de recursos humanos e a sua configuração institucional. Como as escolas do legislativo, os centros de educação continuada, as universidades corporativas, as escolas de administração e as escolas de contas, o Cefor não cabe mais no acanhado modelo do centro de treinamento. No horizonte de atuação do Cefor, há várias possibilidades de reconfiguração. Um dos exemplos mais próximos, enquanto parte da administração pública, é o das escolas de governo, conforme trataremos a seguir.

\section{A evolução do centro de treinamento}

O termo escola de governo não é tão preciso como se poderia em princípio supor. Mesmo quando se limita o seu uso ao campo das instituições governamentais, ainda se tem um conjunto que mistura fundações, autarquias e diretorias, sem falar dos setores ampliados das secretarias de administração ou planejamento. O que os unifica sob a mesma denominação é a função comum de capacitar servidores públicos ou outros profissionais para a atuação pública ou estatal. Dentre esse aparente emaranhado de órgãos públicos, emergem dois modelos do que seria hoje uma escola de governo no Brasil.

O primeiro desses modelos é o que recebe, mais comumente, o nome de escola de governo e tem na Escola Nacional de Administração Pública (Enap) a matriz e o exemplo mais acabado. A Enap foi criada em 1986 sob a tutela da École Nactionale d'Administration (Ena) e, como sua correspondente francesa, destinava-se a formar a classe dirigente da administração pública federal. Tratava-se, na época, da retomada de um projeto dos anos 1930 de construção de uma burocracia estável. Desde o início, o desenvolvimento desse projeto enfrentou conflitos e dificuldades de ordens diversas que culminaram, nos primeiros anos da década de 1990, com diminuição considerável de suas atividades (Pacheco, 2000). A instituição volta a atuar plenamente quando da reforma da administração pública em 1995, seguida da instituição do Plano Plurianual (PPA) em 1999, que levaram a Enap a redirecionar suas atividades de ensino 
para os gerentes da administração pública federal, com ênfase sobre a melhoria da gestão (Hall, 2002).

Atualmente, a Enap define a sua missão em termos de desenvolvimento das "competências de servidores públicos para aumentar a capacidade de governo na gestão das políticas públicas" www.enap.gv.br. Para tanto, oferece quatro programas de capacitação para gestores e técnicos da Administração Pública - Programa de Capacitação em Gestão da Logística Pública; Programa de Capacitação em Gestão de Pessoas; Programa de Capacitação em Gestão do PPA; e Desenvolvimento de Gerentes Operacionais e Supervisores - com cursos presenciais e a distância, dentro de uma estrutura modular. Esses cursos, quando presenciais, são oferecidos em turmas abertas, destinadas a qualquer servidor público, ou fechadas, ou seja, um órgão pode solicitar a oferta de um curso exclusivo para seus servidores, podendo até demandar adequações em um curso pré-existente e, ainda, um curso sob medida para suas necessidades. Além disso, a Enap ministra os cursos de formação inicial para as carreiras de Analista de Planejamento e Orçamento e de Especialista em Políticas Públicas e Gestão Governamental, assim como cursos de pós-graduação lato sensu na área da Gestão Pública. A instituição ainda mantém parcerias com órgãos similares no Brasil e no mundo e uma série de publicações, das quais se destacam a Revista do Serviço Público e os Cadernos ENAP.

Com esse perfil, a Enap e as instituições que lhe são similares parecem se distanciar cada vez mais do modelo do centro de treinamento e assumir uma nova feição para a escola de governo. A diferença, como aponta esquematicamente Zouain (2003), está no público, que passa da massa informe dos servidores públicos em geral para os gerentes. Também se revela na missão que busca a ampliação e o fortalecimento da capacidade de Governo e da administração em lugar da simples formação de dirigentes e técnicos de carreira. Está presente, ainda, nos conteúdos dos cursos, agora voltados para temas como gestão, gerenciamento de projetos, mapeamento de competências e políticas públicas e não mais apenas legislação e contabilidade na administração pública. Enfim, não se quer mais a mera atualização dos servidores, mas sim servidores capazes de tornar o governo mais eficaz.

\section{Os recursos da academia}

Antes da transformação dos centros de treinamento em escolas de governo, havia um outro modelo disponível para a formação de servidores públicos. Trata-se da bem conhecida estrutura das faculdades ou o modelo da instituição acadêmica. Ao seguir esse modelo, as escolas de governo assumem as feições de uma instituição isolada de ensino superior, oferecendo cursos de graduação, pós-graduação lato e stricto sensu em suas áreas de atuação, além de realizar pesquisas e atividades que, grosso modo, podem ser entendidas como extensão. 
Um exemplo desse tipo de instituição é a Escola de Governo Professor Paulo Neves de Carvalho - www.eg.fjp.mg.gov.br, uma diretoria da Fundação João Pinheiro, de Minas Gerais, criada em 1992. O objetivo geral dessa escola de governo, como o de qualquer outra, é o de modernizar e profissionalizar a administração pública. Também consta de seus objetivos a assessoria aos órgãos do governo e o fortalecimento da gestão governamental. Para tanto, ela realiza atividades acadêmicas de ensino, extensão e pesquisa. No caso do ensino, a Escola de Minas Gerais oferece um curso de graduação em Administração Pública que é, na verdade, a formação exigida para o nível inicial da carreira de Especialista em Políticas Públicas e Gestão Governamental do governo de Minas Gerais. O vestibular do curso é, assim, um concurso público para o cargo, cuja nomeação se dá no ato da colação de grau. Em nível de pósgraduação, dispõe de especializações diversas em sua área de atuação, com destaque para o Programa de Especialização em Administração Pública, desenhado para atender aos servidores de nível superior do governo e de outras instituições públicas. As especializações são de amplo acesso, mas a Escola também atende a demandas especificas com turmas fechadas, a exemplo do Curso de Auditoria em Saúde oferecido ao Instituto de Previdência dos Servidores de Minas Gerais. Há, ainda, um mestrado em Administração Pública, criado em 1995, com três áreas de concentração - Gestão da Informação, Gestão de Políticas Sociais e Gestão Econômica.

A extensão se concretiza nos vários cursos de curta duração ministrados dentro do programa de educação continuada da Escola. Nesse caso, merece menção o Programa Gestão Urbana e de Cidades que busca, por meio de cursos, seminários, banco de dados, oficinas, estudos e pesquisas, contribuir para um debate crítico sobre a gestão das cidades. É interessante observar que, por suas características, o público da Escola, seja no ensino, seja na extensão, não se restringe aos servidores públicos; ao contrário, é aberto à sociedade em geral, com a presença destacada de agentes comunitários e profissionais da área privada que prestem serviço ao Estado ou que estejam diretamente ligados aos setores governamentais.

Como seria de se esperar em uma instituição de cunho acadêmico, a Escola publica os textos de conclusão de grau de seus cursos, assim como os resultados de suas pesquisas. No caso das pesquisas, registre-se que elas atendem tanto a questões gerais, a exemplo do estudo Preços do Petróleo e Taxa de Desemprego: evidência para a economia brasileira, quanto a questões específicas do contexto estadual, como é o caso da pesquisa Condições de Vida e Trabalho na Região do Jardim de Teresópolis - Betim, revelando uma temática mais ampla do que é comum nas escolas de governo que evoluem do centro de treinamento.

O traço mais positivo desse tipo de escola de governo é a relativa liberdade de que goza para constituir seus programas, públicos e parcerias frente ao alinhamento quase automático com as políticas de governo a que são submetidas as escolas do tipo centro de treinamento. Entretanto, o preço dessa liberdade é o distanciamento dos núcleos de poder do governo, 
podendo vir a se constituir em instituições com problemas de identidade em sua missão principal de aprimorar a gestão pública. Elas também enfrentam problemas que são comuns às instituições acadêmicas como parcimônia de recursos, corpo funcional reduzido para a amplitude das tarefas e dificuldade em focalizar as ações em uma única direção, como é mais fácil de acontecer com as escolas de governo oriundas dos centros de treinamento.

\section{Reflexão final}

Entre esses dois modelos, para onde se encaminha o Cefor enquanto escola de governo? Aparentemente, o Cefor apropria-se de ambos, incorporando elementos de um e de outro dentro de sua antiga conformação de centro de treinamento. Não é, obviamente, uma solução adequada para um centro de educação continuada com as proporções que o órgão assumiu na Câmara dos Deputados e no campo do Legislativo. A nova configuração do Cefor não precisa seguir necessariamente o modelo de uma ou de outra escola de governo ou mesmo qualquer outro disponível hoje no campo da administração pública. Todavia, não se pode deixar de verificar os limites e as contribuições de cada proposta, até para que se possa ir além da fácil adoção de rótulos na definição de um horizonte de atuação. Nesse sentido, talvez seja relevante observar que, independentemente do modelo, já se preconiza um novo papel para uma escola de governo. Longe de simplesmente formar técnicos competentes para a gestão pública, caberia a uma escola de governo, fundamentalmente "orientar - enquanto órgão de Estado ou voltado para ele - as políticas públicas, a redefinição da cultura política e das formas de vida, articulando, estimulando e coordenando - de forma sistemática - os debates sobre público e privado, novos paradigmas gerenciais, compromisso ético e formação política do cidadão e do servidor público" (Garcia e Sales, 1999, p. 84).

Tomando como ponto de partida esse novo horizonte de atuação para uma escola de governo, o Cefor talvez possa, mais do que ajustar-se ao que já existe, estabelecer uma nova forma de conceber e estruturar órgãos educacionais fora do campo escolar. Para tanto, deve não apenas imbricar capacitação e formação em uma perspectiva maior de educação continuada, mas também cruzar as fronteiras dos públicos e dos saberes compartimentalizados para se afirmar como um locus de reflexão sobre a instituição que o abriga.

\section{Referências}

BRASIL. Decreto no 5.707. Diário Oficial da União - Seção 1 - 24/02/2006 , p. 3.

GARCIA, Maria Vileni e SALES, Ronaldo. O papel da escola de governo na construção de uma nova relação entre Estado e Terceiro Setor: da desconfiança à parceria. R. paran. Desenv., Curitiba, n.96, p. 77-89, maio/ago. 1999. 
HALL, Donald. Desenvolvimento gerencial no setor público: tendências internacionais e organizações-líderes. Cadernos Enap, n. 21, Brasília: ENAP, 2002.

PACHECO, Regina Silvia. Escolas de governo: tendências e desafios - ENAP-Brasil em perspectiva comparada. Revista do Serviço Público, ano 51, n. 2, 2000, p. 3-21.

ZOUAIN, Deborah M. Escolas de governo e escolas de serviço público: limites e problemas. Estudo de caso da FESP/RJ e FUNDAP/SP. VIII Congreso Internacional del CLAD sobre la Reforma del Estado y de la Administración Pública, Panamá, 28-31 Oct. 2003. Anais CLAD, 2003.

Sítios da Internet:

www.enap.gov.br/

www.portalabel.org.br

www.serpro.gov.br

www.planalto.gov.br

www.eg.fjp.mg.gov.br 